\title{
Permanent Partial Horner Syndrome due to SUNA
}

\author{
Sebnem Bicakci Kezban Aslan Yakup Sarica \\ Department of Neurology, Cukurova University, Adana, Turkey
}

Dear Sir,

SUNCT syndrome is characterized by recurrent, short-lasting, unilateral neuralgiform headaches with conjunctival injection and tearing. This definition derives from Sjaastad et al. [1] and is found in the 2nd edition of The International Classification of Headache Disorders (ICHD-II). In clinical practice, this syndrome does not always conform to the specified criteria. Short-lasting Unilateral Neuralgiform headache Attacks with cranial autonomic symptoms (SUNA), as a new definition in the appendix and comments section of the ICHD-II [2], has been noted as a subtype for such divergent cases. Patients may present with only one of the following: conjunctival injection, tearing or other cranial autonomic symptoms such as nasal congestion, rhinorrhoea, or a subform of SUNCT. To date, only 10 cases have been reported by Cohen et al. [3] and Volcy et al. [4].

In this report, we present a male patient who has been followed-up for 4 years due to notable permanent findings. This case was initially considered SUNCT, but was later thought to be consistent with SUNA according to the ICHD-II.

\section{Case Report}

A 43-year-old male suffered from headaches triggered by stress, exhaustion and cutaneous triggering. His attacks, lasting approximately $60 \mathrm{~s}$, were present between 5-15 times per day. Initial site of the pain was the left supraorbital and orbital area. A left-sided conjunctival hyperemia without lacrimation, minimal eyelid edema, and nasal congestion but no change in sweating were detected during the pain period. Indomethacin was administered for approximately 3 weeks at $75 \mathrm{mg} /$ day in the $1 \mathrm{st}, 150 \mathrm{mg} /$ day in the $2 \mathrm{nd}$, and 200 $\mathrm{mg} /$ day in the $3 \mathrm{rd}$ week. There was no response. Gabapentin was then administered at $900 \mathrm{mg} /$ day and the attacks came under control within approximately 1 month. The first attack continued for approximately 13 weeks. Partial Horner syndrome was still present following full recovery from the attack (fig. 1), although no pupillary or eyelid abnormalities were seen on his photo at 23 years of age (fig. 2). All probable causes of Horner syndrome, including topical drugs, were ruled out. All laboratory and imaging tests were normal. No topical medications which might have caused this syndrome had been administered. No change in the Horner syndrome was evident during the entire follow-up period of 4 years. His attacks lasted 2-3 weeks, occurring at least twice a year. The onset of attacks led to immediate admission to our headache polyclinic and to the administration of gabapentin $900 \mathrm{mg} /$ day. To date, medication has been administered regularly without considering spontaneous remission.

The patient has been followed up for 4 years. No changes have been observed in his findings during periodic checkups.

\section{Discussion}

Our case demonstrates typical characteristics of SUNCT from the aspect of conjunctival hyperemia, supraorbital location, palpebral edema, and myosis. The patient never identified tearing during the

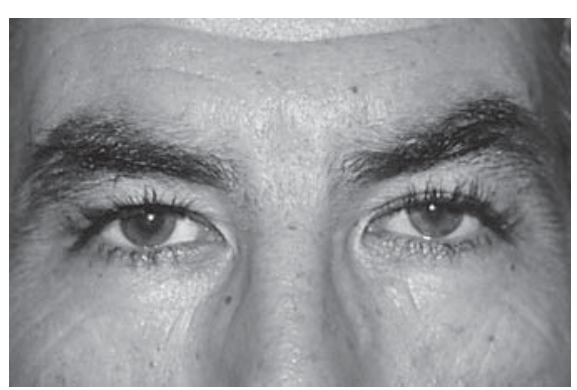

Fig. 1. Myosis and ptosis were present on the left side following recovery from the attack.

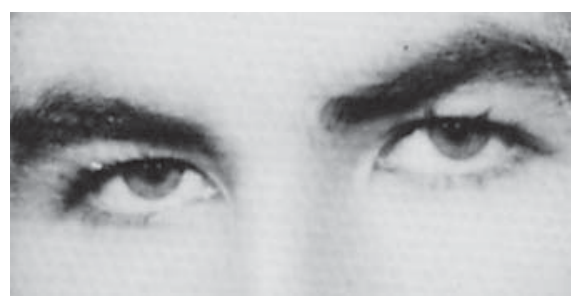

Fig. 2. No sign of Horner syndrome was present on the old photo of the patient at 23 years of age.

attacks. The case was first considered SUNCT, but a SUNA diagnosis was established later according to the ICHD-II [2]. This case is noteworthy not only for its diagnosis, but also for the persistent left palpebral edema and myosis following the attacks (fig. 1). Although very rare, persis-

\section{KARGER}

Fax +4161306 1234 E-Mail karger@karger.ch www.karger.com (c) 2007 S. Karger AG, Basel 0014-3022/07/0582-0118\$23.50/0

Accessible online at:

www.karger.com/ene
Sebnem Bicakci, MD

Department of Neurology

School of Medicine, Cukurova University

TR-01330 Adana (Turkey)

Tel./Fax+90 322338 6290, E-Mail sebnemb@cu.edu.tr 
tent Horner syndrome may be associated with trigeminal autonomic cephalgias [5]. Seven cases, in particular cluster headaches and one case of SUNCT syndrome, have been defined to date [6]. Prakash and Lo [7] have proposed that persistent Horner syndrome might be due to continuous carotid vasodilation during headache attacks, causing a cumulative traumatic effect on sympathetic fibers. As a subtype, a similar effect may be present in SUNA [7].

In our case, autonomic signs were thought to be due to the attacks, because signs of Horner syndrome were not present on previous photographs (fig. 2). There were no other significant causative factors for Horner syndrome such as trauma, cervical lymphadenopathy, infectious disease, use of eye drops, etc. Nor were any radiological abnormalities identified in the patient history.
As in Prakash's case, there was no accompanying anhydrosis. Therefore, it might be assumed that postganglionic sympathetic fibers were affected. Indomethacin was given for differential diagnosis of trigeminal autonomic headaches, but there was no response. Pain attacks did, however, respond to gabapentin. The findings persisted during attack remissions.

\section{References}

1 Sjaastad O, Russell D, Horven I, Bunaes U: Multiple neuralgiaform, unilateral headache attacks associated with conjunctival injection and appearing in clusters: a nosological problem (abstract). Proc Scand Migraine Soc 1978;31.

2 Headache Classification Subcommittee of International Headache Society: The International Classification of Headache Disorders. Cephalalgia 2004;1:23-135.
3 Cohen AS, Matharu MS, Goadsby PJ: Shortlasting unilateral neuralgiform headache attacks with conjunctival injection and tearing (SUNCT) or cranial autonomic features (SUNA) - a prospective clinical study of SUNCT and SUNA. Brain 2006;129:27462760.

4 Volcy M, Tepper SJ, Rapoport AM, Sheftell, Bigal ME: Short-lasting Unilateral Neuralgiform headache Attacks with cranial autonomic symptoms (SUNA) - a case report. Cephalalgia 2005;25:470-472.

5 Sjaastad O, Saunte C, Salvesen R, et al: Shortlasting unilateral neuralgiform headache attacks with conjunctival injection, tearing, sweating, and rhinorrhea. Cephalalgia 1989; 9:147-156.

6 Havelius U: A Horner-like syndrome and cluster headache. What comes first? Acta Ophthalmol Scand 2001;79:374-375.

7 Prakash KM, Lo YL: SUNCT syndrome in association with persistent Horner syndrome in a Chinese patient. Headache 2004; 44:256-258. 